\title{
Uplift of the Longmen Shan and Tibetan plateau, and the 2008 Wenchuan $(M=7.9)$ earthquake
}

\author{
Judith Hubbard, ${ }^{1, *}$ \& John H. Shaw ${ }^{1}$ \\ ${ }^{1}$ Department of Earth and Planetary Sciences, Harvard University, 20 Oxford \\ Street, Cambridge, Massachusetts 02138, USA. \\ *Corresponding author. Email: jhubbard@fas.harvard.edu
}

\begin{abstract}
The Longmen Shan mountain range, site of the devastating 12 May 2008 Wenchuan $(M=7.9)$ earthquake, defines the eastern margin of the Himalayan orogen and exhibits greater topographic relief than anywhere else in the Tibetan plateau. However, before the earthquake, geodetic and geologic surveys measured little shortening across the range front ${ }^{1-3}$, inspiring a vigorous debate about the process by which the topography of the mountain belt is produced and maintained. Two endmember models have been proposed: (1) brittle crustal thickening, in which thrust faults with large amounts of slip that are rooted in the lithosphere cause uplift ${ }^{4}$, and (2) crustal flow, in which low-viscosity material in the lower crust extrudes outward from the Tibetan plateau and inflates the crust north and east of the Himalayas ${ }^{5-7}$. Here we use balanced geologic cross-sections to show that crustal shortening, structural relief, and topography are strongly correlated in the range front. This suggests that crustal shortening is a primary driver for uplift and topography of the Longmen Shan on the flanks of the plateau. The 2008 Wenchuan $(M=7.9)$ earthquake, which ruptured a large thrust fault along the range front causing tens of thousands of fatalities and widespread damage, is an active manifestation of this shortening process.
\end{abstract}

India began colliding with Eurasia over 50 million years ago, progressively accommodating at least $1,400 \mathrm{~km}$ of north-south shortening ${ }^{8}$. This plate collision uplifted the highest mountains in the world and also a vast flat region to the 
north known as the Tibetan plateau. This plateau has an average elevation of over $5,000 \mathrm{~m}$, maintained in part by a $65-75-\mathrm{km}$-thick crust with a complex and heterogeneous three-dimensional structure inferred from tomographic studies. ${ }^{9-11}$

On the eastern side of the Tibetan plateau, the Longmen Shan rise 6,000 $\mathrm{m}$ above the Sichuan basin, exhibiting greater relief than anywhere else on the plateau (Fig. 1). Exhumation rates suggest that the relief has formed since the Miocene epoch ${ }^{12}$. However, geodetic measurements ${ }^{1-3}$ and geomorphic observations ${ }^{13}$ generally agree that east-west shortening across the range and within the basin is very limited $(<3$

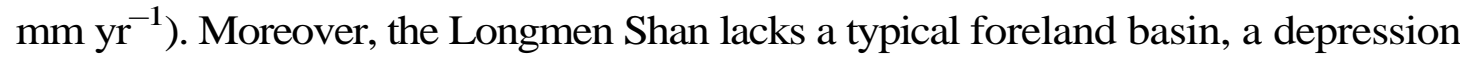
caused by plate loading that typically occurs in front of fold-and-thrust belts ${ }^{14,15}$. As a result, basic and controversial questions persist about how this relief was created and is sustained, fuelling debate about how the broader Tibetan plateau was formed. Are the mountains formed by crustal faulting and shortening ${ }^{4}$, or are they maintained by dynamic pressure from lower-crustal flow ${ }^{5-7}$ ? The second hypothesis argues that lower-crustal material flowing outward from the centre of the plateau is buttressed by the old, strong lithosphere that underlies the Sichuan basin, pushing up on the crust above and maintaining steep topography through dynamic pressure. This model requires no substantial horizontal shortening at the surface, because the upper crust is largely uplifted, but not laterally displaced, by the lower-crustal motion ${ }^{16}$. (Fig. 2)

An important distinction between these two models is that brittle crustal thickening requires horizontal shortening to be related to vertical uplift in the Longmen Shan, whereas lower-crustal flow suggests that the two are largely decoupled $^{16,17}$. Here we aim to quantify past horizontal shortening on the eastern border of the Longmen Shan to determine whether the gradient in horizontal shortening reflects the current topography. Measures of horizontal shortening are derived from structural interpretation of industry seismic reflection profiles and surface geology in the Sichuan basin and the foothills of the Longmen Shan.

Substantial amounts of industry seismic reflection data have been acquired since the 1980s in the Sichuan basin and eastern Longmen Shan to identify petroleum traps; these data offer clear images of faults and related folds in the upper crust (see Supplementary Figs 1 and 2). The lines are supported by a number of wells 
providing chrono-stratigraphic control on the subsurface geology. We use quantitative fault-related folding techniques to interpret these data and construct balanced, retrodeformable cross-sections ${ }^{18,19}$. These balanced sections provide direct measures of shortening and uplift, which we examine in conjunction with topography across the range front.

Deformation in the southwestern Sichuan basin can be separated into six northeast-southwest-striking domains, visible in both the seismic data and satellite images of the surface (Fig. 1). From east to west, these are (1) a set of broad folds, hereafter referred to as the Zigong folds after a city in their vicinity, (2) the Weiyuan anticline, (3) the Longqan anticline, (4) the Emei anticline, (5) the Xiong Po anticline, and (6) the Longmenshan foothills (Fig. 3b). In addition, the strata exhibit a regional west dip of two to three degrees towards the Longmen Shan west of the Weiyuan structure. This dip may be related to loading of the crust by the mountain belt. However, it lacks the typical expression of a foreland basin, perhaps due to the lack of synorogenic sediments, which are not present in the basin.

The six major structural trends are formed by fault-bend or fault-propagation folds rooted in detachments that transfer shortening from the mountain belt towards the east into the Sichuan basin. From the seismic reflection data, we identify three detachment levels, which define the base of the thrust sheets: a shallow detachment 3-5 $\mathrm{km}$ below the surface, an intermediate detachment 5-7 km below the surface, and a deep detachment at least $15 \mathrm{~km}$ deep on the northwestern side of the lines, shallowing to no less than $6 \mathrm{~km}$ to the southeast. Each detachment feeds slip onto thrust ramps that produce upper crustal shortening and uplift the range front of the Longmen Shan. The amounts of slip interpreted on the thrust ramps and detachments are constrained by the offsets of hanging-wall and footwall cut-offs of stratigraphic horizons, as well as the shapes of associated fault-related folds.

We focus our discussion of shortening and structural relief on a regional structural transect (lines $\mathrm{A}-\mathrm{A}^{\prime}$ in Fig. 1) that represents the general style of deformation along the range front. The total shortening measured by line length on the six structures totals $25.8 \mathrm{~km}$, with most taken up across the Longmenshan foothills $(13.3 \mathrm{~km})$ and the Xiong Po backthrust $(\sim 7.4 \mathrm{~km})$, the structures closest to the range front. The Emei, Longqan, Weiyuan and Zigong structures account for 1.0, 1.1, 1.1 and 1.9 
$\mathrm{km}$ of shortening, respectively.

To determine the gradient of shortening, we calculate the percentage shortening for each structural trend. Crustal shortening is defined as the amount of northwest-tosoutheast contraction that has occurred across each of the six major structural domains as the result of folding and faulting. The shortening measurements vary from about $2 \%$ up to $40 \%$, and dramatically increase upon approaching and entering the Longmen Shan. This westward increase in crustal shortening directly corresponds with the rapidly increasing elevations of the range front, suggesting that brittle shortening is closely linked to producing and maintaining the topography of the mountain belt (Table 1 and Fig. 3a).

In addition, we calculate profiles of structural relief along lines $\mathrm{A}-\mathrm{A}$ ' and compare them with topography (Fig. 3c). Structural relief records the total uplift produced by each fault and fold trend in the basin, and thus is considered to be another measure of upper crustal deformation. We quantify structural relief using the deformed shape of the youngest, pre-tectonic Jurassic stratigraphic horizon that is defined by continuous reflections in the industry seismic data. The patterns of structural relief correspond closely with the present-day topography observed along the range front. The magnitudes and gradients in topographic relief are clearly less than the structural relief due to erosion. Nevertheless, the positions of the maxima, minima and gradients in structural relief and topography closely correlate, implying that present-day topography is produced by uplift along faults and folds in the upper crust. We note that the Zigong folds, which represent the westernmost extent of the largely inactive Eastern Sichuan fold belt rather than deformation associated with the Longmen Shan, do not show this correlation.

In summary, our quantitative interpretation of structures in the Sichuan basin and foothills of the Longmen Shan indicates that a large increase in shortening occurs upon approaching the range front. Moreover, structural relief produced by folds and faults is also closely correlated with, and sufficient in magnitude to explain, the topography of the range front. This implies that upper-crustal deformation, decoupled from the lower crust by a series of detachments, is the primary mechanism for generating uplift and topography in the foothills of the Longmen Shan. In the crustal shortening versus lower-crustal-flow debate, it is the range front's reported absence 
of active shortening that underpins the lower-crustal-flow hypothesis, and some models proposed for this lower-crustal-flow process explicitly prescribe no correlation between upper-crustal shortening and topography ${ }^{16}$.

Thus, we interpret our results to obviate the need for lower-crustal flow and inflation to produce and maintain the Longmen Shan range front, and argue that if lower-crustal flow occurs in the interior of the mountain belt, it must somehow be directly coupled to upper-crustal deformation in the range front. Alternatively, further deepening of the active thrust systems and shortening west of our study area, which has been inferred in recent geodetic studies ${ }^{14}$ and documented in geologic mapping ${ }^{20}$, may account for uplift of the plateau in the absence of significant lower-crustal flow.

The Wenchuan $(M=7.9)$ earthquake is a direct manifestation of the active crustal shortening that we suggest produced and supports the Longmen Shan range front. This devastating earthquake occurred on a series of large, crustal thrust faults that form the range front and accommodate crustal shortening immediately west of the area we considered (Fig. 4). From the distribution of large aftershocks and reported surface ruptures, it appears that this earthquake and its aftershocks caused slip on two major faults within this imbricated thrust stack that ramp upward to the surface, as well as others that transfer slip over geologic timescales into the basin on the detachment surfaces documented here.

Thus, the Wenchuan $(M=7.9)$ earthquake documents the role of active crustal shortening in developing and supporting the Longmen Shan range front and the Tibetan plateau, consistent with the results of our analysis that relate crustal shortening to the development of range front topography. This earthquake also clearly illustrates the potential for large and very destructive events on similar active thrust faults that have been observed in other populated regions around the world.

\section{Acknowledgements}

We thank the reviewers, E. Kirby and J. Dolan, for their comments and suggestions. Texaco and the China National Petroleum Corporation provided the seismic data used in this project. 


\section{References}

1. Shen, Z. K., Lu, J. N., Wang, M. \& Burgmann, R. Contemporary crustal deformation around the southeast borderland of the Tibetan Plateau. J. Geophys. Res. 110, 11409, doi:10.1029/2004JB003421 (2005).

2. Meade, B. J. Present-day kinematics at the India-Asia collision zone. Geology $35,81-84$ (2007).

3. Chen, Z. et al. Global Positioning System measurements from eastern Tibet and their implications for India/Eurasia intercontinental deformation. J. Geophys. Res. 105, 16215-16227 (2000).

4. Tapponnier, P. et al. Geology-Oblique stepwise rise and growth of the Tibet plateau. Science 294, 1671-1677 (2001).

5. Royden, L. H. et al. Surface deformation and lower crustal flow in eastern Tibet. Science 276, 788-790 (1997).

6. Burchfiel, B. C. 2003 presidential address: New technology, new geological challenges. GSA Today 14, 4-9 (2004).

7. Bird, P. Lateral extrusion of lower crust from under high topography, in the isostatic limit. J. Geophys. Res. 96, 10275-10286 (1991).

8. Yin, A. \& Harrison, T. M. Geologic evolution of the Himalayan-Tibetan orogen. Annu. Rev. Earth Planet. Sci. 28, 211-280 (2000).

9. Rapine, R., Tilmann, F., West, M., Ni, J. \& Rodgers, A. Crustal structure of northern and southern Tibet from surface wave dispersion analysis. J. Geophys. Res. 108, B22120, doi:10.1029/2001JB000445 (2003).

10. Xu, L., Rondenay, S. \& van der Hilst, R. D. Structure of the crust beneath the southeastern Tibetan Plateau from teleseismic receiver functions. Phys. Earth Planet. Inter. 165, 176-193 (2007).

11. Yao, H., Behein, C. \& van der Hilst, R. D. Surface wave array tomography in SE Tibet from ambient seismic noise and two-station analysis. II. Crustal and 
upper-mantle structure. Geophys. J. Int. 173, 205-219 (2008).

12. Kirby, E. et al. Late Cenozoic evolution of the eastern margin of the Tibetan Plateau: Inferences from ${ }^{40} \mathrm{Ar} /{ }^{39} \mathrm{Ar}$ and (U-Th)/He thermochronology. Tectonics 21 (1), 1001, doi:10.1029/2000TC001246 (2002).

13. Densmore, A. L.et al. Active tectonics of the Beichuan and Pengguan faults at the eastern margin of the Tibetan Plateau. Tectonics 26, TC4005, doi:10.1029/ 2006TC001987 (2007).

14. Burchfiel, B. C. et al. A geological and geophysical context for the Wenchuan earthquake of 12 May 2008, Sichuan, People's Republic of China. GSA Today 18, 4-11 (2008).

15. Burchfiel, B. C. et al. Tectonics of the Longmen Shan and adjacent regions, Central China. Int. Geol. Rev. 37, 661-735 (1995).

16. Clark, M. K., Bush, J. W. M. \& Royden, L. H. Dynamic topography produced by lower crustal flow against rheological strength heterogeneities bordering the Tibetan Plateau. Geophys. J. Int. 162, 575-590 (2005).

17. Medvedev, S. \& Beaumont, C. in Channel Flow, Ductile Extrusion and Exhumation in Continental Collision Zones (eds Law, R. D., Searle, M. P. \& Godin, L.) 147-164 (Geological Society, London, 2006).

18. Shaw, J. H., Connors, C. \& Suppe, J. Seismic Interpretation of Contractional Fault-related Folds: An AAPG Seismic Atlas 1-58 (AAPG, 2005).

19. Suppe, J. Geometry and kinematics of fault-bend folding. Am. J. Sci. 283, 684721 (1983).

20. Chen, S. F. \& Wilson, C. J. L. Emplacement of the Longmen Shan ThrustNappe Belt along the eastern margin of the Tibetan Plateau. J. Struct. Geol. 18, 413-430 (1996). 


\section{List of Table}

Table 1 Shortening measurements for each structure along line A-A'. 


\section{List of Figures}

Figure 1 Map of the Longmen Shan and western Sichuan basin, showing the epicentre and focal mechanism of the 2008 Wenchuan $(M=7.9)$ earthquake, aftershocks, and major faults. $\mathrm{A}-\mathrm{A}^{\prime}$ and $\mathrm{B}-\mathrm{B}$ ' are cross-sections based on seismic reflection profiles used to characterize crustal deformation in this study. Emergent and blind thrusts are distinguished; faults in red are the Beichuan and Hanwang faults, which ruptured in the 2008 Wenchuan earthquake.

Figure 2 Alternative conceptual models for the uplift of the Tibetan plateau and development of the Longmen Shan range front. Top panel, uplift is produced by thrust faulting and crustal shortening ${ }^{4}$. Bottom panel, uplift is produced by inflation of the ductile lower crust $^{5-7}$.

Figure 3 Comparison of crustal shortening and topography along line AA'. See Table 1. a, Percentage shortening is shown as colour bars (alternating green and blue) plotted over topography; we note the dramatic increase in shortening towards the range front. b, Geologic cross-section. c, Topography (black) and structural relief (blue) from structural interpretation. Vertical dashed lines separate the Zigong folds from the rest of the line (see text).

Figure 4 Geologic cross-section B-B' across the location of the 2008 Wenchuan $(M=7.9)$ earthquake. On the basis of the depth and preferred nodal plane of the main shock, the earthquake and its aftershocks appear to have ruptured one or more imbricated thrust and reverse faults in the range front, including the Beichuan faults, of which there are reports of surface rupture. 'CMT' indicates the Global CentroidMoment Tensor (CMT) Project (http://www.globalcmt.org/) Moment Tensor Solution. The Pengguan fault lies south of the Hanwang fault but did not rupture in the earthquake. 
Table 1

\begin{tabular}{llll}
\hline Structure & Shortening $(\mathrm{m})$ & Distance $(\mathrm{km})$ & Shortening $(\%)$ \\
\hline Foothills & 13.3 & 36 & 37 \\
Xiong Po & 7.4 & 30 & 25 \\
Emei & 1.0 & 11 & 9 \\
Longqan & 1.1 & 41 & 2.7 \\
Weiyuan & 1.1 & 69 & 1.6 \\
Zigong & 1.9 & 41 & 4.6
\end{tabular}

The percentage shortening was calculated by dividing shortening by the horizontal width of each structural belt. 


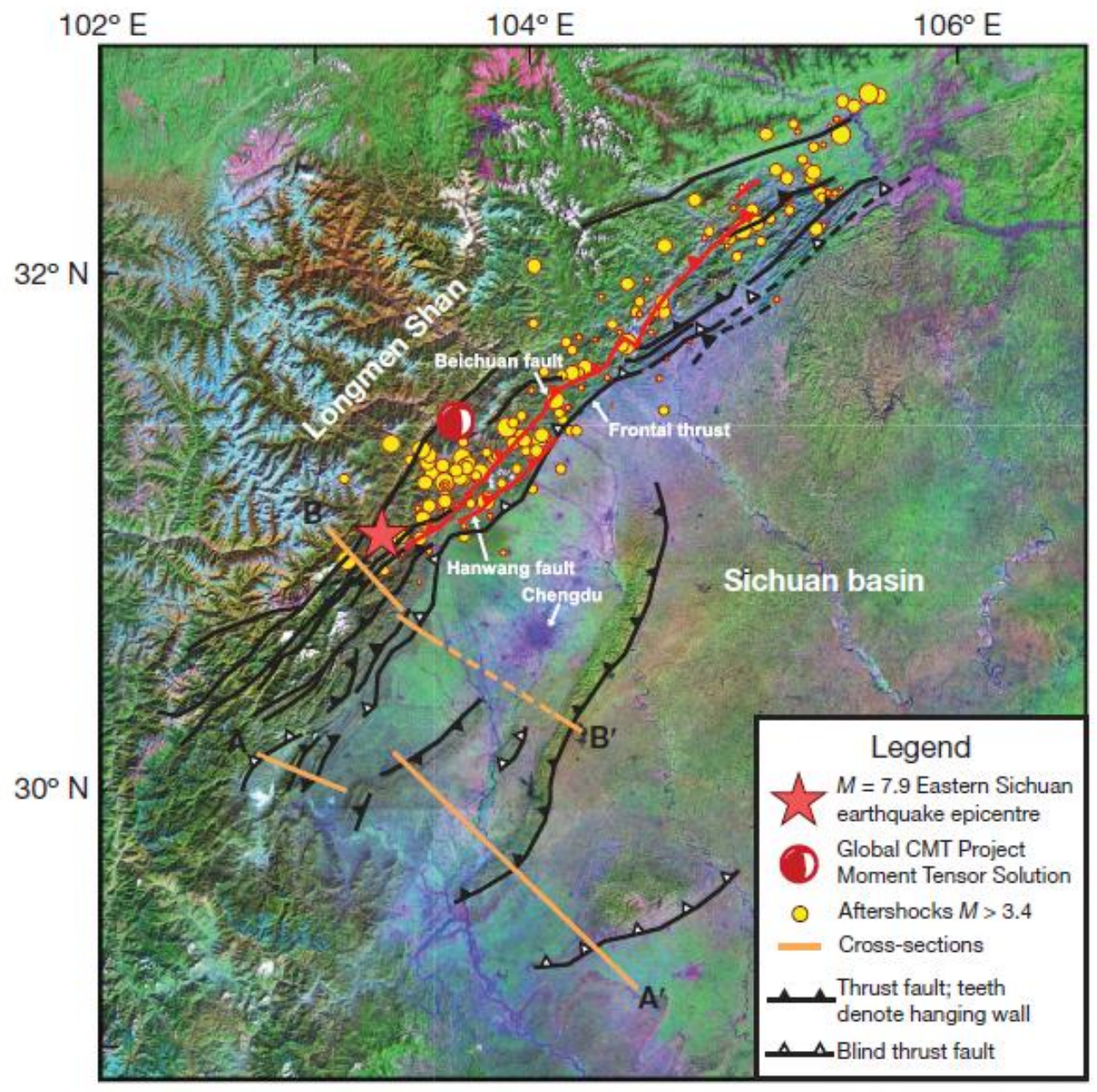

Figure 1 


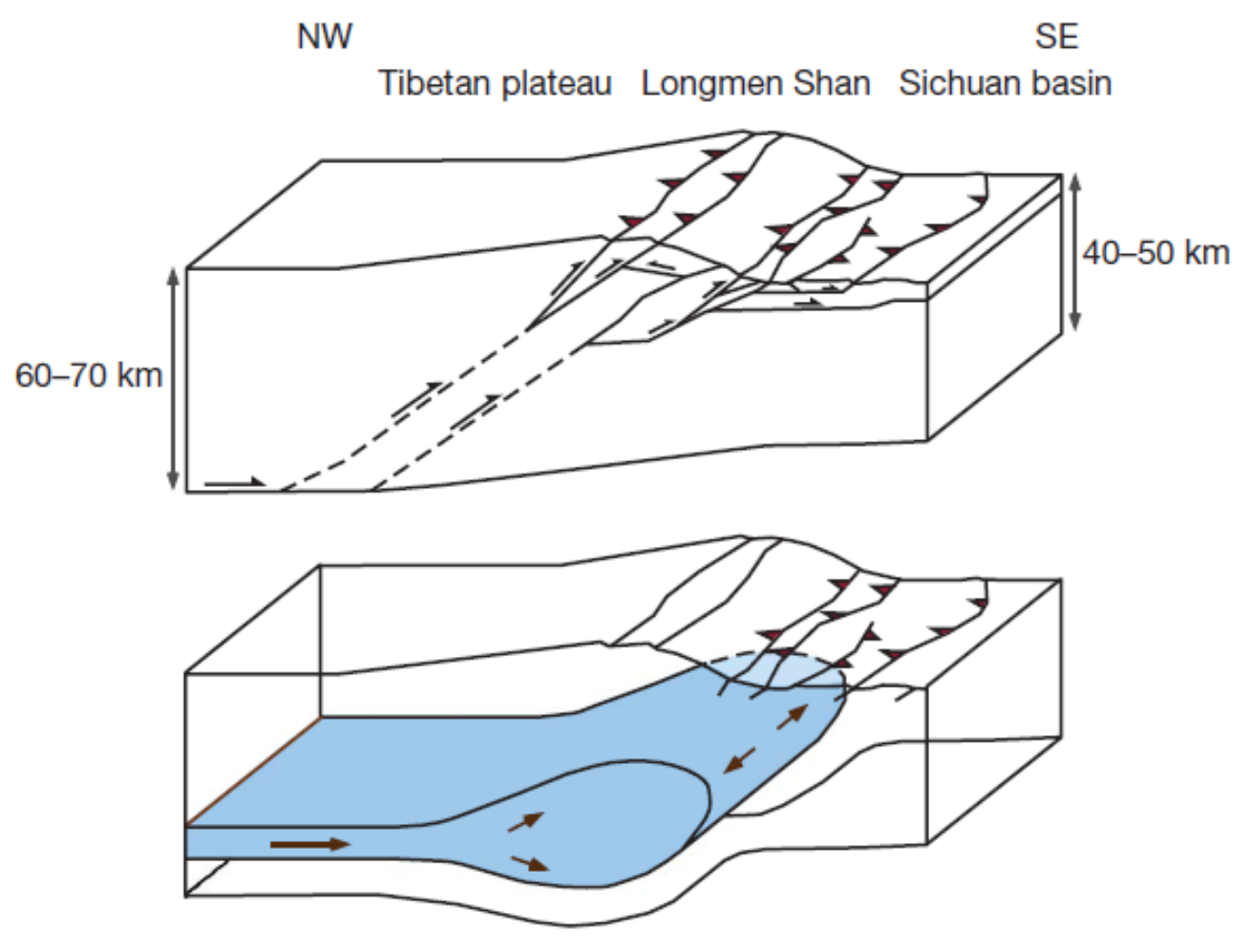

Figure 2 


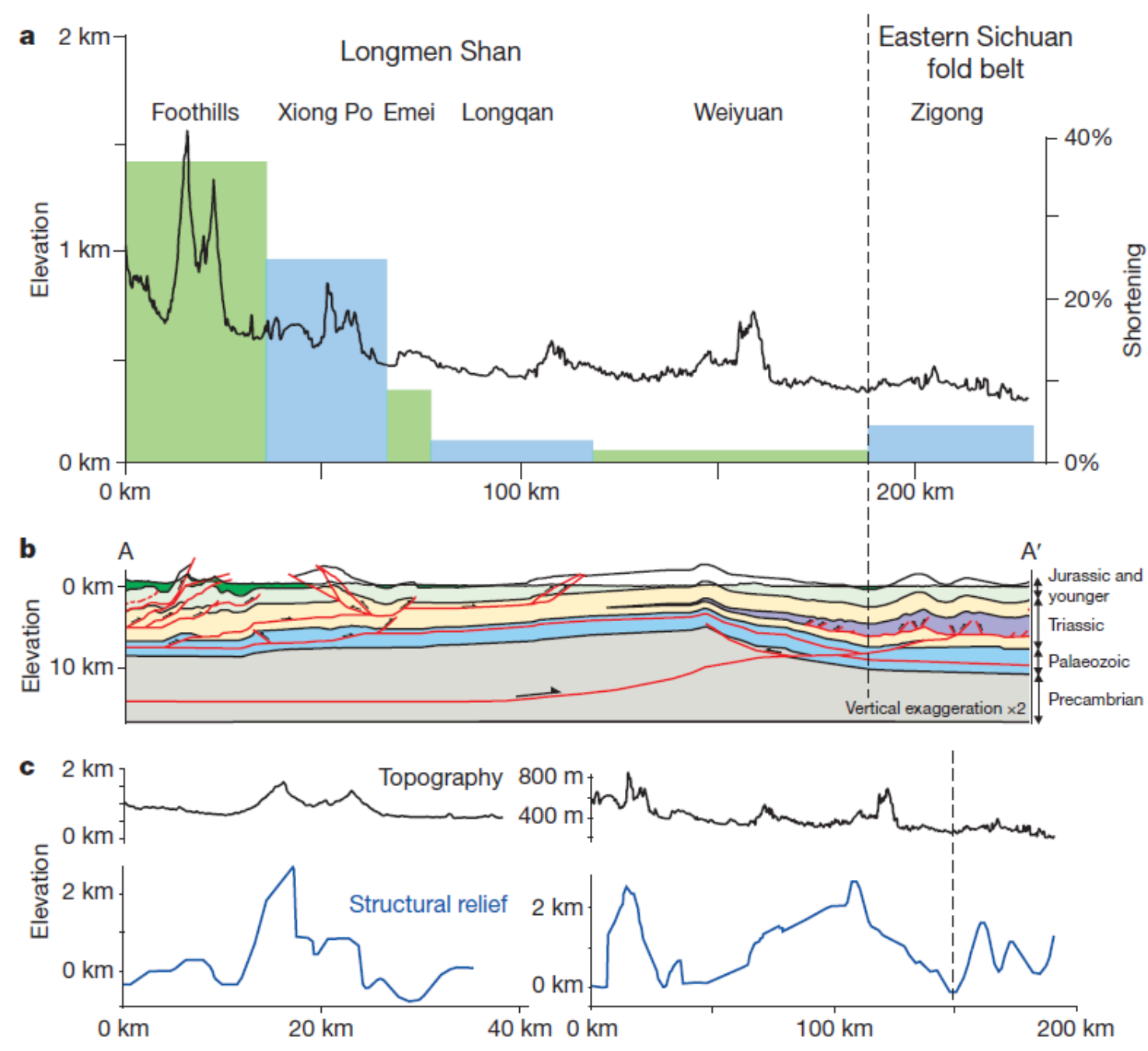

Figure 3 


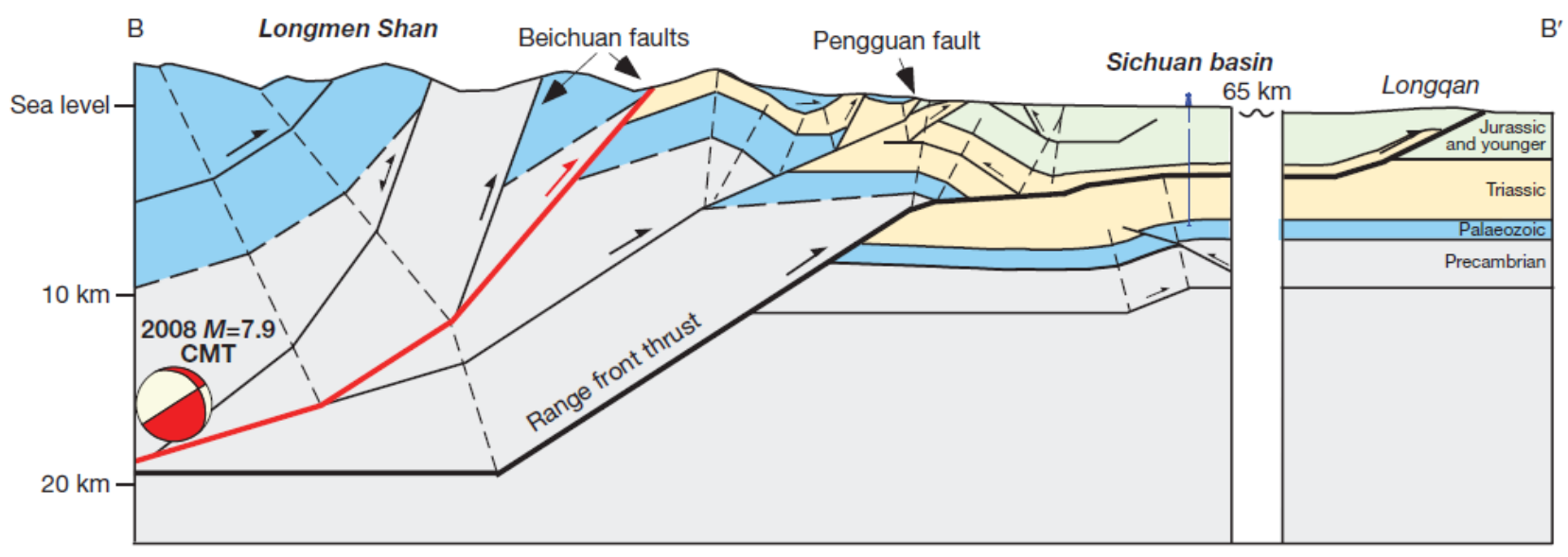

Figure 4 